Article

\title{
Risk Assessment of Flood Disaster Induced by Typhoon Rainstorms in Guangdong Province, China
}

\author{
Jiayang Zhang and Yangbo Chen * \\ School of Geography and Planning, Sun Yat-Sen University, Guangzhou 510245, China; \\ zhangjy225@mail2.sysu.edu.cn \\ * Correspondence: eescyb@mail.sysu.edu.cn; Tel.: +86-020-8411-4269
}

Received: 21 March 2019; Accepted: 8 May 2019; Published: 14 May 2019

\begin{abstract}
China's coastal areas suffer from typhoon attacks every year. Rainstorms induced by typhoons characteristically are high intensity with a large amount of rain and usually induce floods and waterlogging in the affected area. Guangdong province has the highest frequency of typhoon hits in China. It has a special geographical position as well as unique climatic features, but the typhoon flood disaster risk has not been fully assessed in this area. This article attempts to fill this gap by providing a comprehensive risk assessment for the area. By combining the Analytical Hierarchy Process (AHP) and multi-factor analysis through geographic information system (GIS) and the comprehensive weighted evaluation, the typhoon flood disaster risk is evaluated from four different aspects with seventeen indicators. A comprehensive study of the typhoon flood disaster risk is carried out, and the risk maps with a resolution of $1 \mathrm{~km}^{2}$ have been made. There is a good coherence between the typhoon flood risk map and historical records of typhoon floods in Guangdong province. The results indicate that the comprehensive typhoon flood disaster risk in the coastal regions of Guangdong province is obviously higher than in the Northern mountainous areas. Chaoshan plain and Zhanjiang city have the highest risk of typhoon flood disaster. Shaoguan and Qingyuan cities, which are in the Northern mountainous areas, have the lowest risk. The spatial distribution of typhoon flood disaster risks shows that it has certain regulations along the coast and rivers, but it may be affected by economic and human activities. This article is significant for environmental planning and disaster management strategies of the study area as well as in similar climatic regions in other parts of the world.
\end{abstract}

Keywords: typhoon rainstorms; flood disaster; analytical hierarchy process (AHP); comprehensive weighted evaluation (CWE); risk assessment

\section{Introduction}

A typhoon is one of the most destructive disasters, which usually causes floods, storm surges and mudslides [1-3]. Heavy rainfall phenomena occur frequently because of typhoons' strong ascending motion and sufficient water vapor. Typhoon rainstorms have the features of high frequency, strong suddenness, a wide influence range, and a high disaster intensity [4]. The center of a typhoon rainstorm can drop 100-300 millimeters of rain a day, sometimes as much as 500-800 millimeters. When a typhoon makes landfall, the rainstorm intensity and the possibility of a flood disaster increase due to topographical influences $[5,6]$. China is frequently affected by typhoons, and, on average, nine typhoons per year make landfall in China [7-9]. In China, rainstorms caused by typhoons account for $52.7 \%$ of all rainstorms, which is more than half of the total annual rainstorms $[7,10]$. The frequent occurrences of typhoon rainstorms and floods indicate that it is not realistic to predict and prevent the occurrence of typhoons and rainstorms completely and accurately. However, if effective disaster management strategies are adopted, the huge losses caused by typhoon floods can be avoided or 
reduced. Therefore, it is of great practical significance to accomplish a risk analysis and risk map compilation of typhoon rainstorm flood disasters to decrease disastrous losses from typhoon rainstorms and floods [11]. Guangdong province is close to the South China Sea and has a high drainage density, so typhoon flood cases appear more frequently in this province than in other provinces, and the number of disasters is increasing year by year $[12,13]$. Therefore, assessment of the typhoon flood risk is necessary for Guangdong province $[14,15]$.

The study of disaster has a long history, but the study of disaster risk assessment originated in the middle of the last century [16]. Early studies on disaster risk assessment methods mainly focused on qualitative assessment methods, but due to the uncertainty of disaster assessment, the qualitative assessment could not meet the research needs; thus research gradually moved from qualitative methods to a combination of qualitative and quantitative methods, or fully quantitative methods [17-20]. At present, risk assessments are based on four main methods: (1) Mathematical statistics, a method usually used to calculate the intensity and frequency of disaster occurrence from historical disaster data and loss data [21,22]; (2) an indicators system, which usually selects reasonable disaster indicators and determines the weight of each indicator to build a risk assessment model and then conduct a comprehensive risk assessment [8,23-26]; (3) RS-GIS technique, in which the satellite remote sensing data are processed and analyzed to determine the flood area and disaster high-risk area with the help of GIS technology [27,28]; and (4) scenario simulation, a method that conducts hydrological and hydrodynamic models to simulate flood scenarios [29-31]. Lots of studies show that the second disaster risk assessment method can reflect the regional risk situation on a macro level, and it has been widely applied because it is simple to conduct. There are several ways to conduct the indicators system method, such as fuzzy comprehensive evaluation (FCE), principal component analysis (PCA), gray relative analysis method (GRA), and comprehensive weighted evaluation (CWE) [32-34]. Among these methods, CWE combined with the analytic hierarchy process (AHP) is commonly used to assess the flood disaster risk [26,35-41].

The purpose of this study was to establish a regional model of typhoon flood risk zones in Guangdong province. Semi-quantitative estimates of natural risk assessment are considered useful when the possibility of accessing multi-source data is limited $[26,42,43]$. Therefore, the semi-quantitative method was chosen. We selected 17 factors that impact the typhoon flood disaster risk and used the AHP to determine the weight of each factor. Then, we used comprehensive evaluation techniques to assess the typhoon flood disaster risk and obtain a risk level map with a higher spatial resolution $\left(1 \mathrm{~km}^{2}\right)$ than that of previous research whose space scales were usually administrative divisions. The rest of the paper is organized as follows: Section 2 introduces the geographical situation, climatic environment, population and economy of Guangdong province. Section 3 mainly introduces the data and methods adopted in this research, including establishment of indicators system and building the comprehensive superposition model. Section 4 shows standardization results and the calculation of each factor's weight, besides, the risk level of typhoon flood disaster and its aspects in Guangdong province are presented in this part, and then the accuracy of the risk map is validated with historical records. Section 5 summarizes the process and draws the conclusions, aiming at summarizing a set of risk grades of flood disaster caused by typhoons in coastal areas to provide a basis for the deployment and prediction of flood control and risk resistance work.

\section{Study Area}

Guangdong Province is located in the Southern part of China near the South China Sea, spanning $109^{\circ} 45^{\prime}-117^{\circ} 20^{\prime} \mathrm{E}$ and $20^{\circ} 09^{\prime}-25^{\circ} 31^{\prime} \mathrm{N}$ (Figure 1 ). The whole region covers approximately 179.7 thousand $\mathrm{km}^{2}$, accounting for $1.87 \%$ of the total area of China. Topographically, Guangdong province's higher area is in the North, and its lower area is in the South, so the North area is mostly mountainous and hilly and the South is covered by plains. The Pearl River delta plain is the largest delta plain in Guangdong province; it is open terrain and is easily waterlogged. The climate presents typical subtropical monsoons, and it ranks first among all provinces of China for the number of 
typhoons that make landfall in China every year. The precipitation from July to September is mainly brought by typhoons, accounting for $40-50 \%$ of the annual precipitation in the Southern area and $30 \%$ in the Northern mountainous area of Guangdong Province [44]. According to The flood, drought and wind disasters in Guangdong, the major floods in the Pearl River Delta in 1994 (No. 9403), 1915 (No. 1506), 1949 (No. 4902), and 1833 were predominantly caused by typhoon rainstorms.

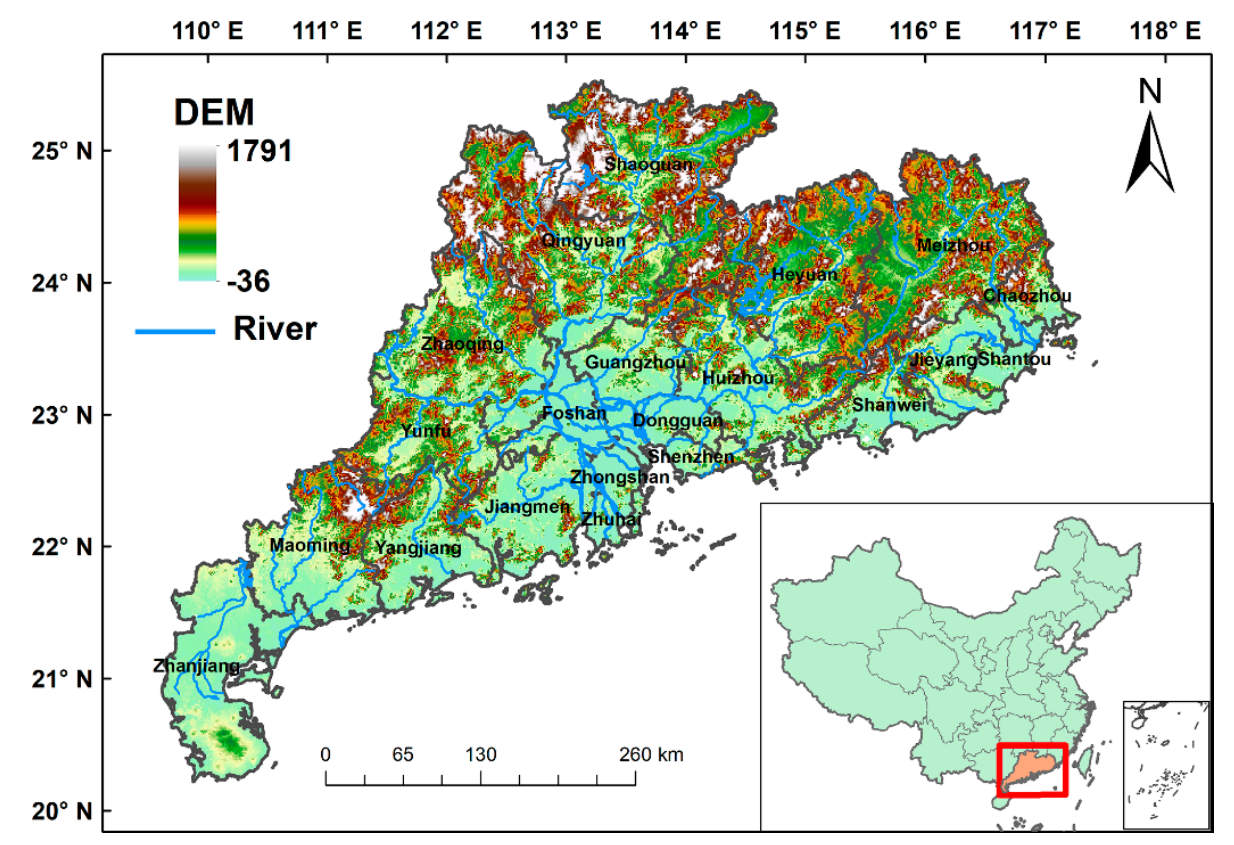

Figure 1. Location and terrain properties of the study area.

Guangdong Province, with its rapid economic development, is one of the fastest growing provinces of China in terms of the progress of urbanization. The population of Guangdong is about 111.69 million (until the end of 2017), and the population in cities is 78.02 million, accounting for $69.85 \%$ of the total. Major cities of Guangdong province are distributed in Pearl River Delta, including Guangzhou, Shenzhen, Foshan, Dongguan, Zhongshan, Zhuhai, Jiangmen, Zhaoqing, Huizhou. In the process of rapid urbanization, land use changes lead to increases in impervious areas such as roads and houses and decreases in urban natural vegetation and river networks. The above urbanization process leads to a decline in the urban drainage capacity. After typhoon rainstorms, the interception, depression filling, and infiltration of the underlying surface decrease, and the runoff is increased while concentration time is shortened. Most cities in Guangdong province are located in low-lying areas such as Pearl River Delta, and these areas are highly urbanized and populated, which making them more vulnerable to typhoon-induced rainstorms and floods [13].

\section{Data and Methodology}

\subsection{The Model of Typhoon Flood Risk Assessment}

\subsubsection{The Theory of Typhoon Flood Risk Assessment}

Risk assessment of natural disasters refers to the assessment and estimation of the intensity of natural disaster factors and the potential disaster degree, which is the application of risk analysis technology in natural disaster science [45]. The natural and social attributes of natural disasters should be taken into account in risk assessment [46,47]. Typhoon flood disasters are a kind of natural disaster, so they are also considered from natural and social attribute points of view. Considering the natural attributes, including the severity of typhoon flood hazard causing factors and the sensitivity of hazard breeding environments, these two aspects directly affect the formation and risk level of a disaster. The 
severity of a typhoon flood hazard causing factor mainly refers to the risk factors that may cause the flooding of farmlands and houses, as well as urban waterlogging and property or personnel losses. The sensitivity of a hazard breeding environment refers to the promotion and inhibition of typhoon flood disasters. Considering the social attributes, including the vulnerability of hazard bearing objects and hazard prevention and mitigation capability, these two aspects directly reflect the ability of the region to respond to an emergency as well as its post-disaster recovery capability. The vulnerability of a hazard bearing objects refers to the extent to which people and property in the risk assessment area suffer losses in the event of a typhoon flood. Hazard prevention and mitigation capability refers to disaster prevention and post-disaster recovery capability, which are related to the installation of hydrological stations and medical facilities as well as personnel allocation and traffic conditions in disaster areas. Based on the above analysis, the risk of typhoon flood disaster can be regarded as a composite function with four aspects, as shown in the following formula:

$$
\operatorname{TFDR}=\left(H^{w h}\right)\left(S^{w s}\right)\left(V^{w v}\right)\left(1-R^{w r}\right)
$$

where, TFDR (Typhoon Flood Disaster Risk) represents the comprehensive risk index of typhoon flood disasters. The smaller of the value of TFDR is, the smaller the comprehensive index of typhoon flood disaster risk is and vice versa. H, S, V, and R represent four aspects of typhoon flood risk assessment: The severity of hazard causing factors, the sensitivity of the hazard breeding environment, the vulnerability of hazard bearing objects, and the capability for hazard prevention and mitigation. In addition, wh, ws, wv, and wr are the corresponding weights of each evaluation aspect.

\subsubsection{Data Acquisition}

We collected sufficient data in different fields including meteorology, hydrology, geography, topography, and statistics. Then a database has been established in a geospatial environment. The meteorological data in Guangdong Province were obtained from the National Meteorological Information Center during 1988-2017, which includes 36 meteorological stations [48]. Typhoon data were downloaded from the China Meteorological Administration (CMA) Tropical Cyclone Data Center $[49,50]$. The land use and land cover data and administrative division data were provided by the Chinese Academy of Sciences [51]. Digital elevation model data were selected from the Shuttle Radar Topography Mission (STRM) system of digital elevation model data (90 m resolution) [52]. Social and economic data were collected from the Statistical Yearbook of Guangdong Province (2017) and the Guangdong statistical information website [53]. Population density data were collected from the Gridded Population of the World (GPW) of Socioeconomic Data and Applications Center (SEDAC) [54]. Road data were taken from OpenStreetMap [55].

\subsubsection{Establishment of the Indicators System}

In this study, four aspects of risk assessment $(\mathrm{H}, \mathrm{E}, \mathrm{V}$, and $\mathrm{R})$ were disaggregated into more specific indicators, and seventeen factors were selected based on literature reviews. Each indicator of the different risk assessment aspects is shown in Figure 2.

As Figure 2 shows, the hazard aspect includes four indicators, which are the mean maximum wind, typhoon frequency, mean daily rainfall, and frequency of heavy rainfall. The mean maximum wind and typhoon frequency reflect the destruction of typhoon wind on the underlying surface. The mean daily rainfall and frequency of heavy rainfall are the two factors that contribute most to disasters, and they represent the impact of a typhoon rainstorm. There are 36 meteorological stations in Guangdong province, and these four indicators were all identified from meteorological data. The typhoons which passed through Guangdong were identified from the typhoon data of the CMA. Typhoon frequency is the number of typhoons that passed through each city in Guangdong province. Additionally, the typhoon-induced rainstorms that influence Guangdong province were filtrated by the characteristics of each typhoon that passed through Guangdong and the $500 \mathrm{~km}$ buffer zone around 
Guangdong. Heavy rainfall frequency refers to the frequency of mean daily rainfall greater than $50 \mathrm{~mm}$.

The sensitivity aspect includes four indicators: Elevation, slope, drainage density, vegetation coverage. Elevation and slope reflect the topography of a disaster-prone environment, while drainage density and vegetation coverage reflect the surface of a disaster-prone environment.

The vulnerability aspect includes four indicators, which are population density, industrial production, cultivated land, and urbanization density. The population density is used to reflect the impact on human life, industrial production and cultivated land are used to reflect the impact on industrial and agricultural production, and urbanization density reflects the phenomenon of urban waterlogging in urbanized areas.

As for the restorability aspect, we used road density and drainage density to represent the emergency response, GDP per capita, hospital bed capacity, and the number of medical staff to represent the recovery capability. Hence, typhoon flood disaster risk is the result of the combined action of these factors [56].

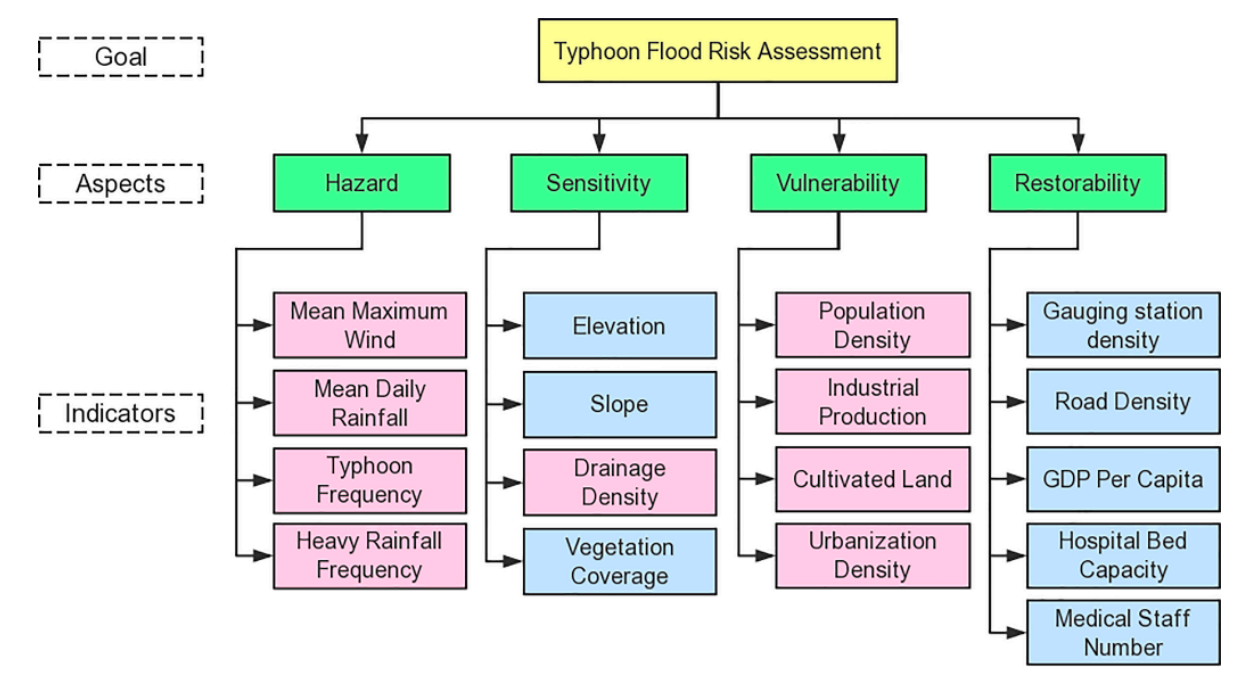

Figure 2. Hierarchy of the typhoon flood risk multi-factor system in Guangdong Province. Yellow represents the goal-typhoon flood risk assessment, green represents four aspects in the assessment, and pink and blue are the factors used to construct the assessment model. Besides, pink factors have positive effects on risk, while blue factors have negative effects.

\subsection{The Methods Used in the Typhoon Flood Risk Assessment}

\subsubsection{GIS Spatial Interpolation}

Spatial interpolation is an important method for the spatial analysis of geographic information systems. This method can be used to deduce the position and characteristics of unknown points based on known points, and it is a method to extend points to the surface. The spatial interpolation method is mainly used for raster data analysis. The most widely used spatial interpolation methods include Thiessen Polygons, Inverse Distance Weighted (IDW), Kriging interpolation, and Spline Function. In this study, IDW interpolation was carried out for the spatial interpolation of discrete data related to the mean maximum wind, mean daily rainfall, and frequency of heavy rainfall to obtain regionally continuous raster data.

IDW interpolation is an interpolation method that uses the distance search strategy to select the interpolation reference point. The closer the unknown point is to the interpolation point, the greater 
the contribution to the interpolation result will be, and thus, the higher the weight will be. The IDW interpolation formula is as follows:

$$
Z\left(x_{0}\right)=\left(\sum_{i=1}^{n} \frac{Z_{i}}{d_{i}^{m}}\right)\left(\left(\sum_{i=1}^{n} \frac{1}{d_{i}^{m}}\right)\right.
$$

where $Z\left(x_{0}\right)$ is the predicted value of the estimated point $x_{0}, Z_{i}$ is the measured value of the given point $i, n$ is the number of given points, $d_{i}$ is the distance between the estimated point $x_{0}$ and given point $i, \mathrm{~m}$ is the power, $\frac{1}{d_{i}^{m}}$ is the weight based on distance.

\subsubsection{Standardization}

Natural disaster risk assessment indicators are from multiple sources. After data processing, each assessment factor has different dimensions and magnitude orders, it is impossible to directly compare them and calculate. In order to compare all evaluation indexes uniformly, it is necessary to normalize them, so that each index value is converted to a range [0,1]. In the assessment, indicators can be divided into positive indicators and negative indicators, which have opposite effects on typhoon rainstorm flood disaster. Therefore, different formulas should be adopted for calculation. The positive index has an aggravating effect on typhoon flood disaster, that is, the greater the value is, and the more harmful it will be. In this paper, the minimum method (Equation (3)) was used for positive indicators. The negative index has a mitigating effect on typhoon rainstorm flood disaster, that is, the greater the value is, and the lower the harm will be. In this paper, the maximum method (Equation (4)) is adopted for s negative indicators. The classes of positive indicators are shown in Figure 2 in pink; on the contrary, negative indicators are shown in blue.

$$
\begin{aligned}
& Y_{i}=\frac{X_{i}-\min _{(i)}}{\max _{(i)}-\min _{(i)}} \\
& Y_{i}=\frac{\max _{(i)}-X_{i}}{\max _{(i)}-\min _{(i)}}
\end{aligned}
$$

where, for the indicator $i, Y_{i}$ is a standardized value, $X_{i}$ is an initial value, $\min _{(i)}$ is the minimum value, and $\max _{(i)}$ is the maximum value.

\subsubsection{Analytic Hierarchy Process (AHP)}

The American operational research expert T. L. Saaty put forward AHP in the 1970s [57]. This method can quantify qualitative problems and has been successfully applied to natural disaster risk studies [57-59]. The main procedure is to divide the level according to the correlation of each factor and then determine the importance between two elements of the same level. Saaty proposed a comparative scale which was composed by integer numbers of $1-9$, where 1 means that the compared factors have the same importance, while 9 means that some factors are much more important than others [60]. We evaluated the relative importance of risk factors based on Saaty's method. Then, a judgment matrix was constructed to rank the evaluation indicators and to determine each evaluation indicator's weight [61]. Finally, to check the consistency, if the consistency ratio (CR) was less than 0.1, the judgment matrix was deemed to be of satisfactory consistency, and if not, it needed to be adjusted or abandoned.

\subsubsection{The Comprehensive Weighted Evaluation (CWE)}

The comprehensive weighted evaluation method selects several evaluation factors that can reflect the research problem, and comprehensively considers the influence of each factor on the research problem, weighting the evaluation factors, finally obtains the evaluation result after comprehensive 
consideration [62]. In this paper, GIS and comprehensive evaluation method are combined, which is clear and easy to understand. The input data is a set of spatial data with the same evaluation criteria, after grouping, standardization, weighting and calculating in raster environment, one or more "comprehensive index map(s)" are output. The final product is typically presented as a map(s), with each grid cell getting a score based on a range of weights specified [63]. The overall performance index $A_{j}$ for each aspect can be calculated using a formula

$$
A_{j}=\sum_{\substack{i=1 \\ j=1,2,3,4}}^{n} W_{i j} Y_{i j}
$$

In this paper, $\mathrm{j}$ is an integer of $1-4$ representing different criteria (hazard, sensitivity, vulnerability, and restorability). The weights $\left(W_{i j}\right)$ are non-negative and add up to 1 , and $Y_{i j}$ is the standardization value of an indicator on a scale of $0-1$, where 1 represents the best performance. The larger the value of $A_{j}$ is, the higher the risk of typhoon flood disaster is, and the more likely the typhoon flood disaster is to occur in this region.

\section{Results and Discussions}

\subsection{Standardization and Weight Determination}

\subsubsection{Standardization}

The standardizations of each indicator are shown in Figures 3-6, and it should be noted that there are two different methods of standardization that are aimed at positive indicators and negative indicators, respectively.

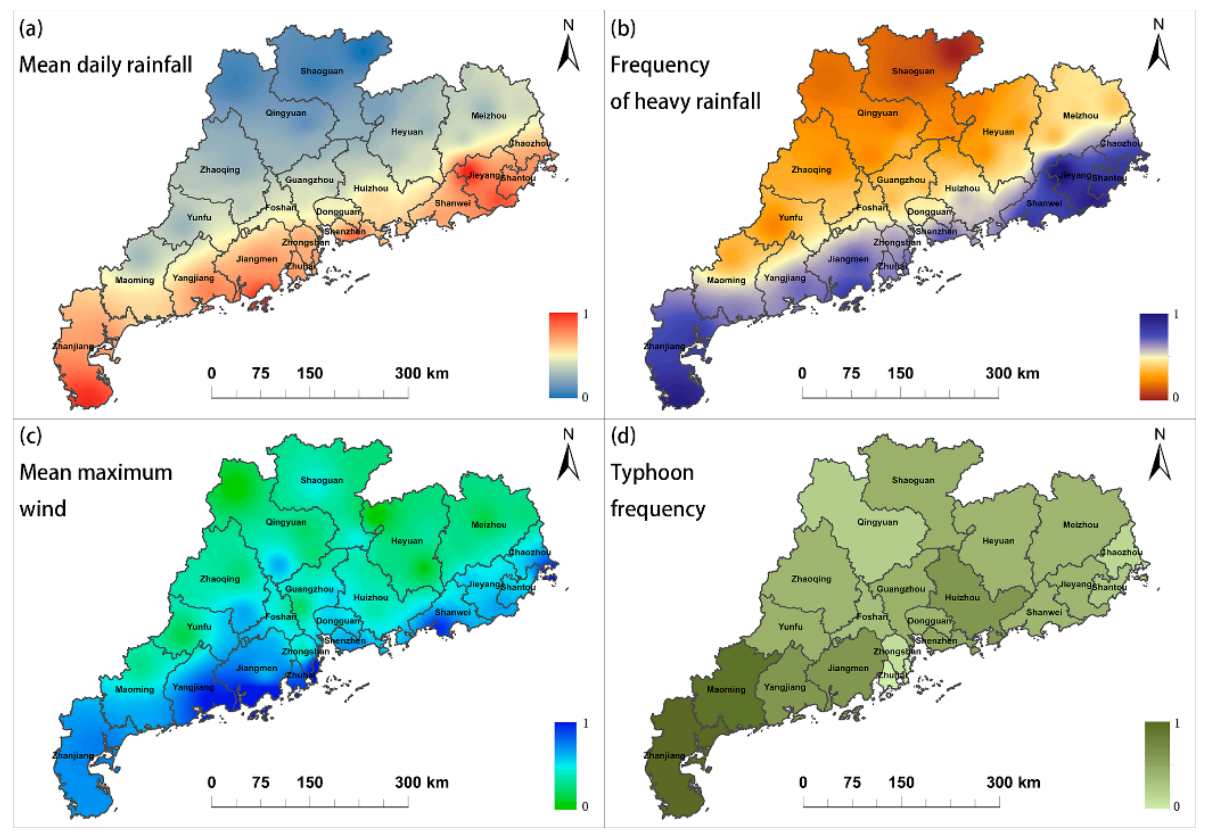

Figure 3. Standardized hazard indicators: (a) mean daily rainfall, (b) frequency of heavy rainfall, (c) mean maximum wind, and (d) typhoon frequency. 


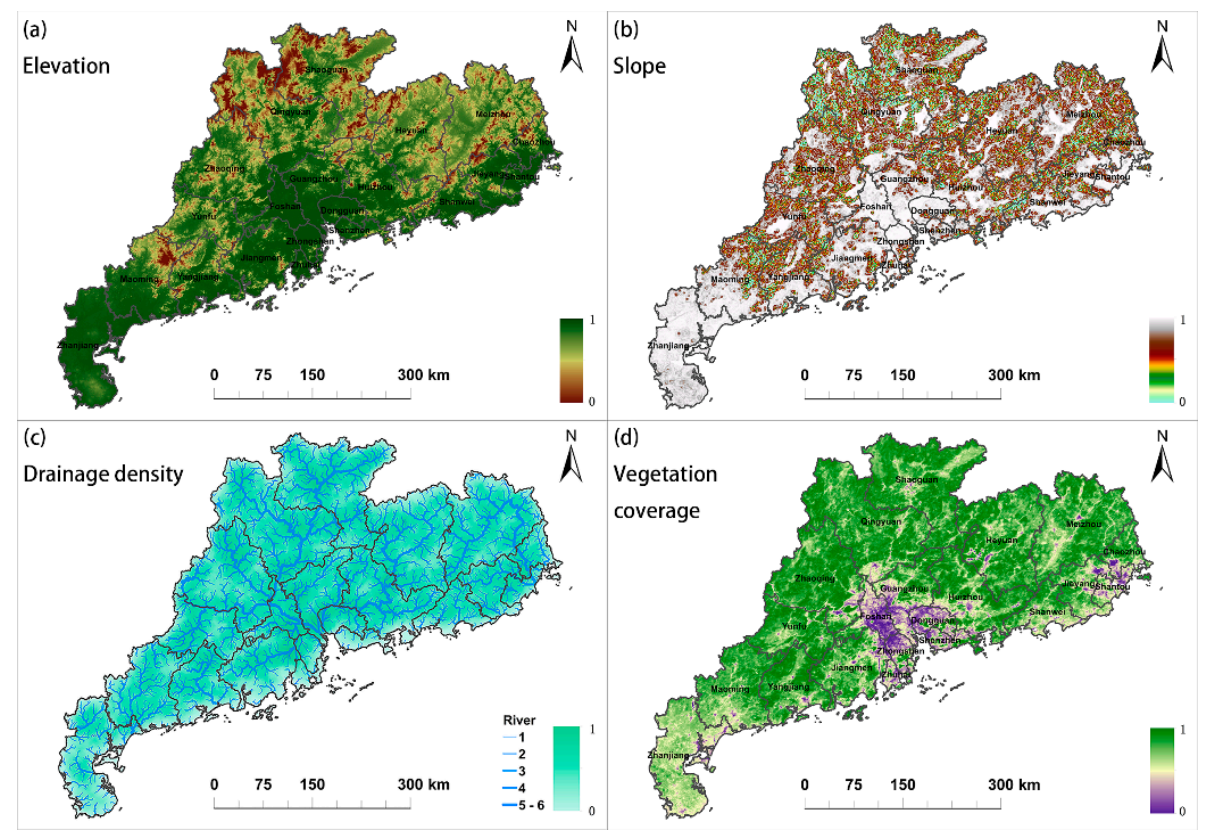

Figure 4. Standardized sensitivity indicators: (a) Elevation, (b) slope, (c) drainage density, and (d) vegetation coverage.

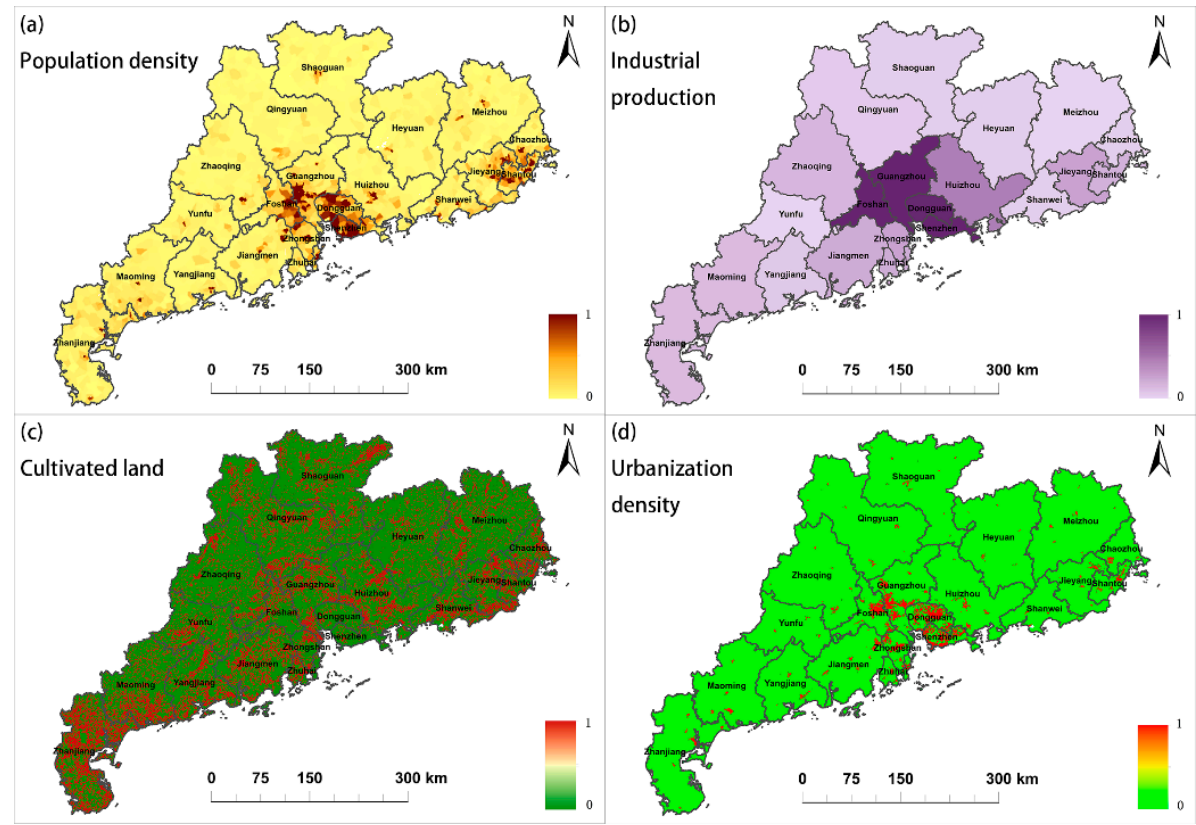

Figure 5. Standardized vulnerability indicators: (a) Population density, (b) industrial production, (c) cultivated land, and (d) urbanization density. 


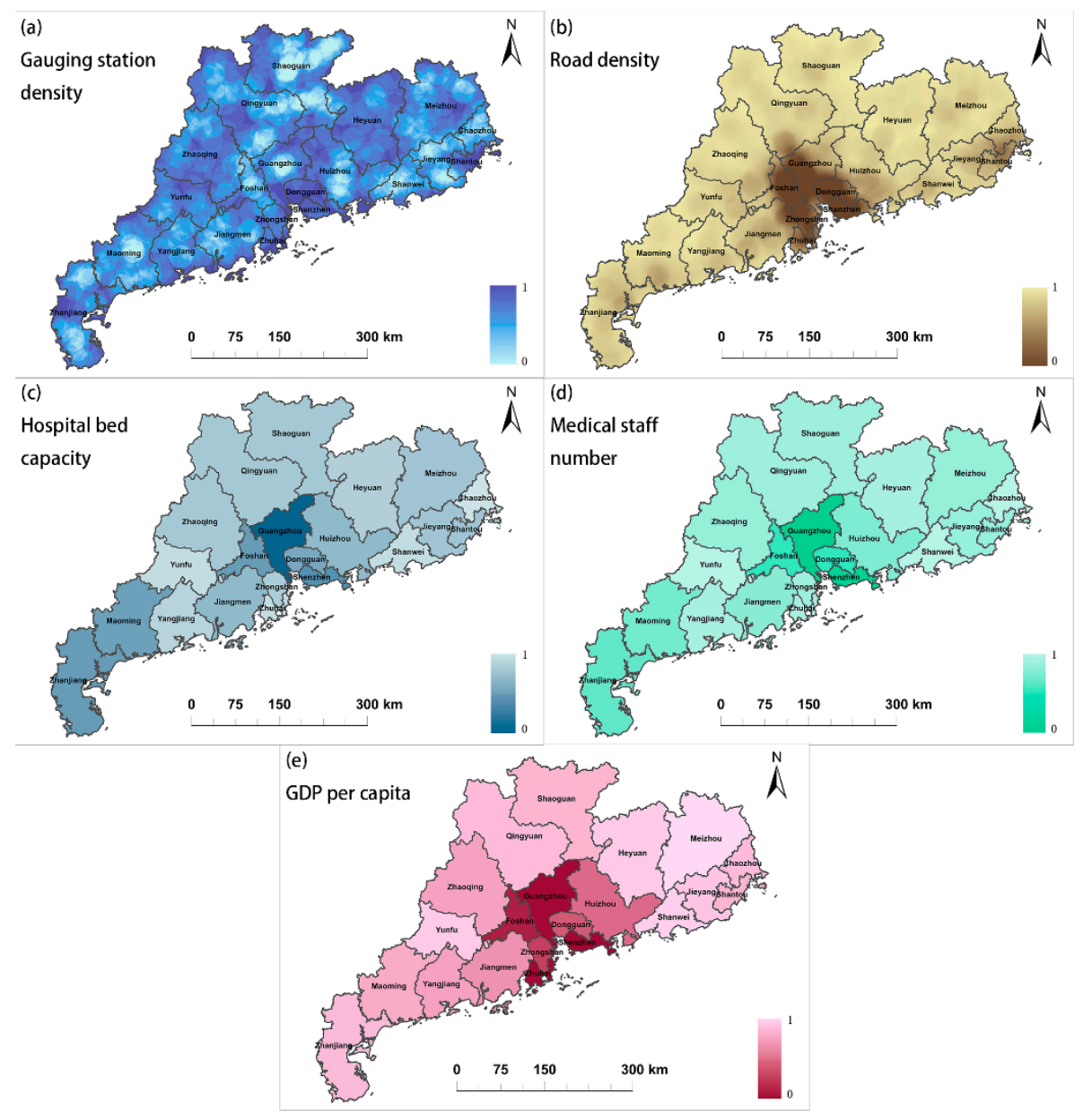

Figure 6. Standardized restorability indicators: (a) gauging station density, (b) road density, (c) hospital bed capacity, (d) medical staff number, and (e) GDP per capita.

\subsubsection{Determination of Weights}

There are four aspects including seventeen indicators in typhoon flood disaster risk assessment. The AHP method was used to determine the weights of the evaluation indicators. By pairwise comparison with each aspect and their indicators, the judgment matrixes were constructed to rank the evaluation indicators and to determine each evaluation indicator's weight. Due to the space limitation, the judgment matrixes are shown in the Appendix A. The consistency ratio (CR) and the largest eigenvalue of judgment matrixes were shown in Table 1 . The CR of each judgment matrixes were all less than 0.1 , so the judgment matrixes were deemed to be of satisfactory consistency. Finally, we calculated the weights of each aspect and their indicators based on the judgment matrixes, the weights are shown in Table 2.

Table 1. Consistency ratio and the largest eigenvalue of the judgment matrix.

\begin{tabular}{cccc}
\hline Assessment Objectives & Consistency Ratio (CR) & $\lambda_{\max }$ & Weight \\
\hline Comprehensive risk & 0.0235 & 4.0627 & 1.0000 \\
Hazard risk & 0.0179 & 4.0477 & 0.5074 \\
Sensitivity risk & 0.0029 & 4.0078 & 0.2108 \\
Vulnerability risk & 0.0268 & 4.0716 & 0.1858 \\
Restorability risk & 0.0451 & 5.2019 & 0.0960 \\
\hline
\end{tabular}


Table 2. The weights of the four aspects, the aspect weights, and the overall weight of each indicator in the multi-factor system.

\begin{tabular}{|c|c|c|c|c|c|c|c|}
\hline Aspect & Indicator & $\begin{array}{l}\text { Aspect } \\
\text { Weight }\end{array}$ & $\begin{array}{l}\text { Overall } \\
\text { Weight }\end{array}$ & Aspect & Indicator & Weight & $\begin{array}{l}\text { Overall } \\
\text { Weight }\end{array}$ \\
\hline \multirow{4}{*}{$\begin{array}{l}\text { Hazard } \\
(0.5074)\end{array}$} & $\begin{array}{l}\text { Frequency of } \\
\text { heavy rainfall }\end{array}$ & 0.5871 & 0.2979 & \multirow{4}{*}{$\begin{array}{l}\text { Vulnerability } \\
(0.1858)\end{array}$} & $\begin{array}{l}\text { Population } \\
\text { density }\end{array}$ & 0.5402 & 0.1004 \\
\hline & $\begin{array}{l}\text { Mean daily } \\
\text { rainfall }\end{array}$ & 0.2560 & 0.1299 & & $\begin{array}{l}\text { Industrial } \\
\text { production }\end{array}$ & 0.1767 & 0.0328 \\
\hline & $\begin{array}{l}\text { Typhoon } \\
\text { frequency }\end{array}$ & 0.0991 & 0.0503 & & Cultivated land & 0.1568 & 0.0291 \\
\hline & $\begin{array}{c}\text { Mean maximum } \\
\text { wind }\end{array}$ & 0.0578 & 0.0293 & & $\begin{array}{l}\text { Urbanization } \\
\text { density }\end{array}$ & 0.1262 & 0.0235 \\
\hline \multirow{5}{*}{$\begin{array}{l}\text { Sensitivity } \\
(0.2108)\end{array}$} & $\begin{array}{l}\text { Drainage } \\
\text { density }\end{array}$ & 0.5305 & 0.1118 & \multirow{5}{*}{$\begin{array}{c}\text { Restorability } \\
(0.0960)\end{array}$} & $\begin{array}{l}\text { Gauging station } \\
\text { density }\end{array}$ & 0.3943 & 0.0378 \\
\hline & Slope & 0.2556 & 0.0539 & & Hospital bed & 0.2280 & 0.0219 \\
\hline & $\begin{array}{l}\text { Vegetation } \\
\text { coverage }\end{array}$ & 0.1374 & 0.0290 & & $\begin{array}{c}\text { capacity } \\
\text { Medical staff } \\
\text { number }\end{array}$ & 0.1774 & 0.0170 \\
\hline & \multirow[t]{2}{*}{ Elevation } & \multirow[t]{2}{*}{0.0765} & \multirow[t]{2}{*}{0.0161} & & Road density & 0.1261 & 0.0121 \\
\hline & & & & & GDP per capita & 0.0742 & 0.0071 \\
\hline
\end{tabular}

As Table 2 shows, the sum of indicators' weights in each aspect was equal to 1.0. It can be seen that the hazard aspect had a heavier weighting than the three other aspects in the multi-factor system. Because the severity of hazard-causing factors plays an important role in disaster risk, it directly determines the level of disaster threat. Theoretically, the frequency of heavy rainfall is the number one factor that leads to rainstorms and floods. Meanwhile, the bigger the frequency of heavy rainfall is, the higher the hazard risk is. Then, sensitivity and vulnerability follow; they also play important roles in the indicator system. Among them, sensitivity and population density are of great importance in each aspect. In terms of the restorability aspect, the gauging station density is the most important factor. Overall, the four factors at the top of the list are the frequency of heavy rainfall, the mean daily rainfall, the drainage density, and the population density. They are the most important factors whose weights exceed 0.1 in the indicator system, especially the frequency of heavy rainfall, the weight of which is close to 0.3 .

\subsection{The risk Assessment of Typhoon Flood Disaster}

After the determination of indicator, standardization, and weighting indicators, all weighted indicator maps were overlaid using addition function in Raster Calculator of ArcGIS 10.2 software which provided a raster environment [62]. The risk indexes of four aspects were primarily calculated and the comprehensive risk of typhoon flood disaster was obtained after the weighted synthesis of the evaluation results of the four risk assessment aspects. In this study, there are five categories of risk-very high, high, medium, low, and very low-using the natural breaks method [64]. The risk levels of the four aspects and each level of risk coverage are shown in Table 3.

As Table 3 shows, the hazard causing factor risk values range from 0.04-0.90. Disregarding pixels with zero values, the closer these numbers are to 1 , the higher the risk is. Very low, low, medium, and high risk zones make up $14.82 \%, 28.72 \%, 22.93 \%$, and $18.97 \%$ of the study area, respectively. The very high risk area accounts for $14.56 \%$. The spatial distribution of risk factors of different levels is shown in Figure 7a. As the figure shows, the very high and high risk areas are mainly located in coastal cities, and the very high risk areas are mainly in Zhanjiang, Jiangmen, Shantou, Shanwei, and Jieyang. The very low risk areas are mainly located in the Northern mountainous area of Guangdong province; Qingyuan and Shaoguan cities account for a large proportion of these areas. 
Table 3. The risk levels and each level of risk coverage for the four risk assessment aspects.

\begin{tabular}{cccc}
\hline Four Aspects & Risk Value Range & Level & Coverage (\%) \\
\hline & $0.04-0.20$ & Very low & 14.82 \\
The severity of hazard & $0.20-0.35$ & Low & 28.72 \\
causing factors & $0.35-0.50$ & Medium & 22.93 \\
& $0.50-0.65$ & High & 18.97 \\
& $0.65-0.90$ & Very high & 14.56 \\
\hline The sensitivity of the & $0.16-0.50$ & Very low & 13.76 \\
hazard breeding & $0.50-0.60$ & Low & 32.14 \\
environment & $0.60-0.70$ & Medium & 37.51 \\
& $0.70-0.80$ & High & 13.98 \\
& $0.80-0.96$ & Very high & 2.61 \\
\hline The vulnerability of & $0-0.10$ & Very low & 69.99 \\
hazard bearing objects & $0.10-0.20$ & Low & 24.70 \\
& $0.20-0.30$ & Medium & 4.45 \\
& $0.30-0.40$ & High & 0.70 \\
The capability for hazard & $0.40-0.80$ & Very high & 0.16 \\
prevention and & $0.16-0.40$ & Very low & 1.66 \\
mitigation & $0.40-0.60$ & Low & 3.21 \\
& $0.60-0.75$ & Medium & 15.09 \\
& $0.75-0.85$ & High & 39.91 \\
& $0.85-1.00$ & Very high & 40.13 \\
\hline
\end{tabular}

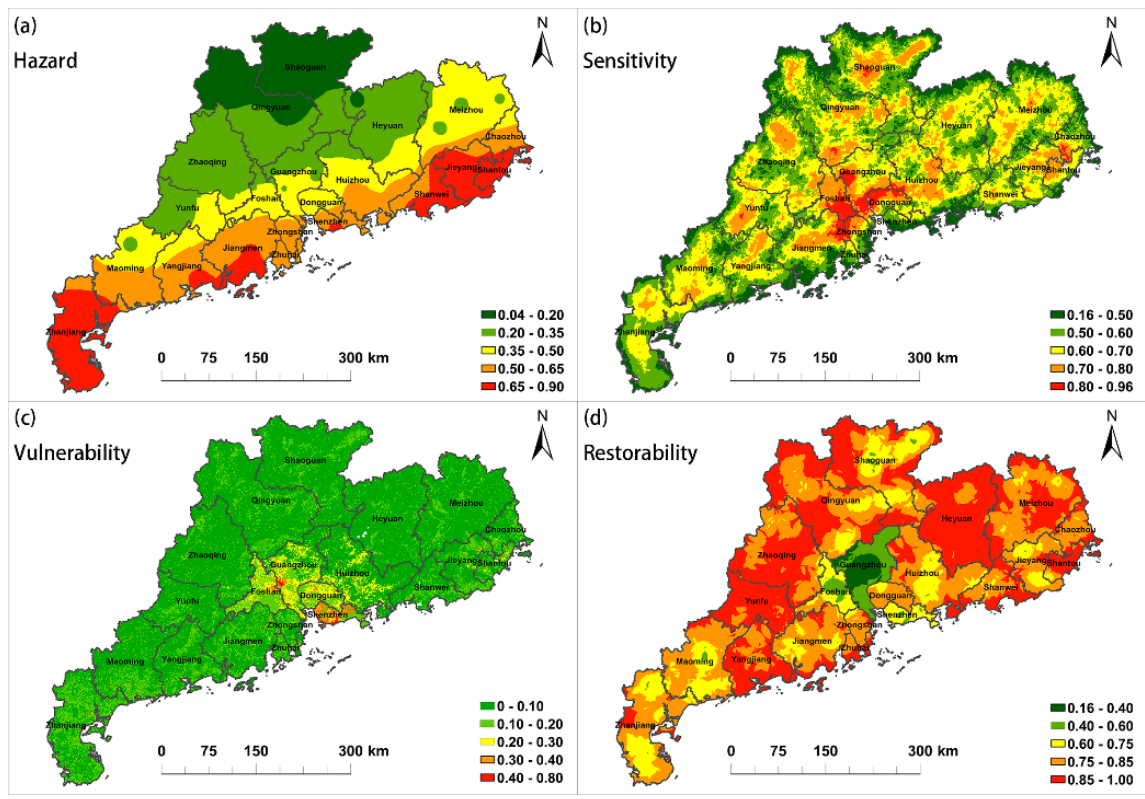

Figure 7. Different risk levels' spatial distribution of four typhoon flood risk assessment aspects: (a) hazard, (b) sensitivity, (c) vulnerability, (d) restorability.

The sensitivity index values range from $0.16-0.96$, with low, medium, and high risk zones accounting for $32.14 \%, 37.51 \%$, and $13.98 \%$ of the study area, respectively. The very low and very high risk area account for $13.76 \%$ and $2.61 \%$. The assessment result of environmental sensitivity is also shown in Figure $7 \mathrm{~b}$. Very high and high risk areas are mainly located in the Pearl River Delta and distributed along the river networks of Guangdong province. Very high areas are mainly in Guangzhou, Foshan, Zhongshan, and Dongguan, which are mainly concentrated in the Pearl River Delta.

The exposure vulnerability index values range from $0-0.80$. Very low risk areas account for the largest proportion of $69.99 \%$, and the low risk area comes in second place, accounting for $24.70 \%$; these 
two levels account for $94.69 \%$ of the study area. Medium, high, and very high risk zones make up $4.45 \%$, $0.70 \%$, and $0.16 \%$, respectively. The assessment result of the hazard-affected bodies' vulnerability is shown in Figure 7c. The medium to very high risk areas are mainly located in the Pearl River Delta, including Shenzhen, Guangzhou, Foshan and Dongguan, while the very high risk areas are mainly located in Shenzhen and Guangzhou. This is mainly because these cities have large proportions of the population and relatively developed economies, so they are relatively vulnerable to disasters.

The restorability values range from $0.16-1.00$. The lower the restorability value is, the higher the risk is. The proportion of very low, low, medium, high, and very high risk zones are $1.66 \%$, $3.21 \%, 15.09 \%, 39.91 \%$, and $40.13 \%$. We can also see the spatial distribution of the capability of hazard prevention and mitigation in Figure 7d. In terms of the restorability, the very low risk areas are mainly located in the cities around Pearl River Delta, especially in Guangzhou and Foshan. This is because Guangzhou, as the capital of Guangdong province, has the highest medical level, a developed road network, and a high per capita GDP.

After obtaining the risk index maps of the four aspects, the general risk assessment map of typhoon flood disaster was weighted by stacking the risk maps of the four aspects. Then, we used the natural breaks method to distinguish the risk value into five levels. As shown in Table 4, the risk values range from $0.17-0.80$, disregarding pixels with zero values, and the closer these numbers are to 1 , the more likely typhoon flood disaster happens. A proportion of $16.63 \%$ of the study area was of very low risk. Low, medium, and high risk zones account for $30.37 \%, 18.82 \%$, and $19.77 \%$, respectively, and the very high risk area is $14.41 \%$.

Table 4. The risk levels and each level of risk coverage for typhoon flood comprehensive risk assessment.

\begin{tabular}{ccc}
\hline Typhoon Flood Risk Value Range & Level & Coverage (\%) \\
\hline $0.17-0.32$ & Very low & 16.63 \\
$0.32-0.40$ & Low & 30.37 \\
$0.40-0.47$ & Medium & 18.82 \\
$0.47-0.55$ & High & 19.77 \\
$0.55-0.80$ & Very high & 14.41 \\
\hline
\end{tabular}

According to the above classification, the typhoon flood risk index map can be shown (Figure 8). Most of the Guangdong Province are found between low and high zones. Near the coastline (Zhanjiang, Jieyang) or adjacent to the river (Pearl River Delta), the area of high risk zones is larger than others. Because the values of some hazard and sensitivity indicators are high, such as the frequency of heavy rainfall and the drainage density, which leads to high susceptibility to typhoon flooding when combined with high sensitivity values. Although Zhanjiang City is not near a river network, the areas with very high risk are still large because of the high typhoon frequency. So, high frequencies of typhoons and heavy rainfall as well as high drainage density are the reasons for high typhoon flood risk, and also the reason why the high risk areas are mainly distributed especially in the coastal zone.

As natural disaster risk assessments in most studies are always accomplished by administration cell, the risk index values of typhoon rainstorm flood disaster in Guangdong province are also analyzed for the administrative cities [62]. Table 5 summarizes the percentages of each city under different typhoon flood risk levels. As shown in Table 5, there are four cities with more than $50 \%$ very high-risk areas: Shantou, Jieyang, Zhanjiang, and Shanwei. Nine cities have mainly high risk areas, among which a high typhoon flood risk is present in more than $50 \%$ of the area for six cities and $39 \%$ to $50 \%$ of the area in three cities. Only two cities have a predominantly medium risk level, four cities have a predominantly low risk level, and two cities in the mountain area (Qingyuan and Shaoguan) have a very low risk level. Moreover, cities located on the coast of Guangdong Province are at a high or very high risk level. Table 6 shows ten cities which has more than $50 \%$ high or very high risk areas. Due to the high risk of typhoon flood disaster in these cities, it is necessary to conduct in-depth studies on these cities in the future and focus on disaster prevention. 


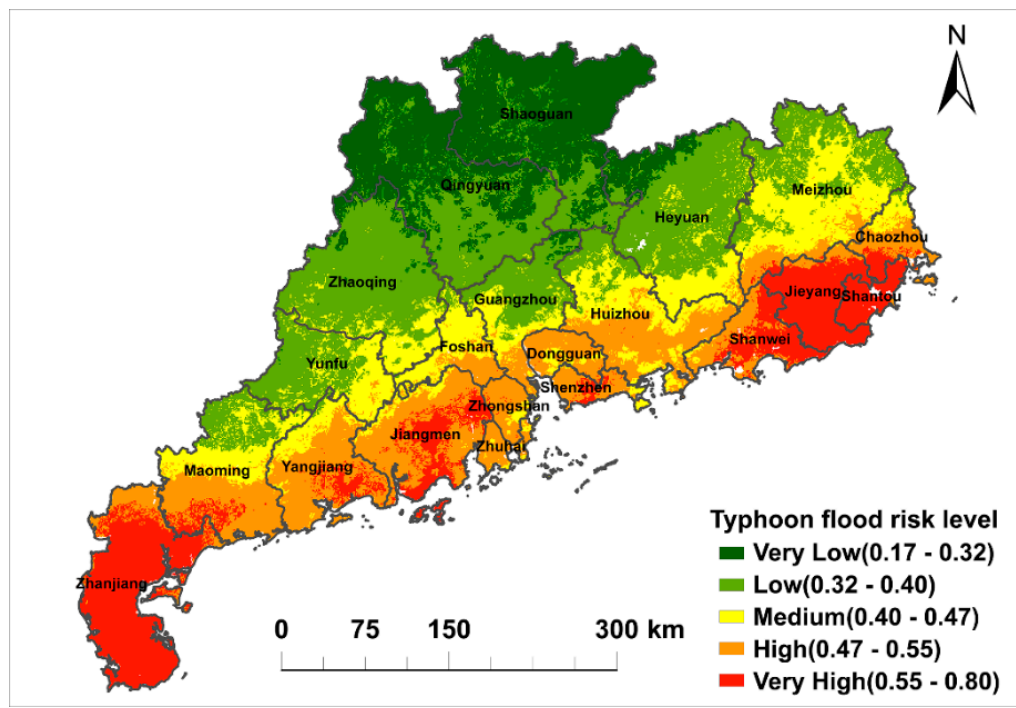

Figure 8. Different risk levels' spatial distribution of typhoon flood disaster.

Table 5. Percentage of each city with different typhoon flood risk levels.

\begin{tabular}{ccccccc}
\hline City & $\begin{array}{c}\text { Very Low } \\
\text { Risk (\%) }\end{array}$ & $\begin{array}{c}\text { Low Risk } \\
\mathbf{( \% )}\end{array}$ & $\begin{array}{c}\text { Medium } \\
\text { Risk (\%) }\end{array}$ & $\begin{array}{c}\text { High Risk } \\
\mathbf{( \% )}\end{array}$ & $\begin{array}{c}\text { Very High } \\
\text { Risk (\%) }\end{array}$ & Main Level \\
\hline Shantou & 0.00 & 0.00 & 0.00 & 2.55 & 97.45 & Very high \\
Jieyang & 0.00 & 0.00 & 0.30 & 10.15 & 89.55 & Very high \\
Zhanjiang & 0.00 & 0.00 & 0.00 & 13.66 & 86.34 & Very high \\
Shanwei & 0.00 & 0.00 & 2.95 & 41.30 & 55.76 & Very high \\
Zhuhai & 0.00 & 0.00 & 14.06 & 85.94 & 0.00 & High \\
Zhongshan & 0.00 & 0.00 & 13.06 & 84.34 & 2.60 & High \\
Dongguan & 0.00 & 0.00 & 16.59 & 82.32 & 1.09 & High \\
Shenzhen & 0.00 & 0.00 & 11.83 & 68.56 & 19.61 & High \\
Yangjiang & 0.00 & 1.97 & 20.19 & 65.54 & 12.30 & High \\
Jiangmen & 0.00 & 0.00 & 8.49 & 59.84 & 31.66 & High \\
Chaozhou & 0.00 & 4.69 & 26.12 & 49.20 & 19.99 & High \\
Huizhou & 0.02 & 16.43 & 40.62 & 42.88 & 0.05 & High \\
Maoming & 0.00 & 20.95 & 31.47 & 39.48 & 8.10 & High \\
Foshan & 0.00 & 6.32 & 65.81 & 27.79 & 0.08 & Medium \\
Meizhou & 0.00 & 39.64 & 49.31 & 10.04 & 1.02 & Medium \\
Zhaoqing & 6.71 & 77.12 & 16.17 & 0.00 & 0.00 & Low \\
Heyuan & 12.95 & 66.45 & 19.44 & 1.16 & 0.00 & Low \\
Yunfu & 0.10 & 60.76 & 37.58 & 1.56 & 0.00 & Low \\
Guangzhou & 4.49 & 58.59 & 26.81 & 10.11 & 0.00 & Low \\
Qingyuan & 56.91 & 42.94 & 0.14 & 0.00 & 0.00 & Very low \\
Shaoguan & 82.06 & 17.94 & 0.00 & 0.00 & 0.00 & Very low \\
\hline
\end{tabular}


Table 6. Ten cities with larger typhoon flood risk areas.

\begin{tabular}{cc}
\hline Four cities with more than $\mathbf{5 0 \%}$ of very high risk & Percentage (\%) \\
\hline Shantou & 97.45 \\
Jieyang & 89.55 \\
Zhanjiang & 86.34 \\
Shanwei & 55.76 \\
\hline Six cities with more than $\mathbf{5 0 \%}$ of high risk areas & Percentage (\%) \\
\hline Zhuhai & 85.94 \\
Zhongshan & 84.34 \\
Dongguan & 82.32 \\
Shenzhen & 68.56 \\
Yangiang & 65.54 \\
Jiangmen & 59.84 \\
\hline
\end{tabular}

\subsection{Validation}

In order to verify the accuracy of the typhoon flood risk assessment model, this paper collected the records of rainstorm disasters induced by typhoons in Guangdong province from China's flood and drought disaster bulletin from 2000-2017, and 77 flood event records were found. The locations of relevant records were marked in ArcGIS10.2 to obtain the distribution map of historical typhoon floods, which were superimposed with the typhoon flood risk map of Guangdong province, as shown in Figure 9.

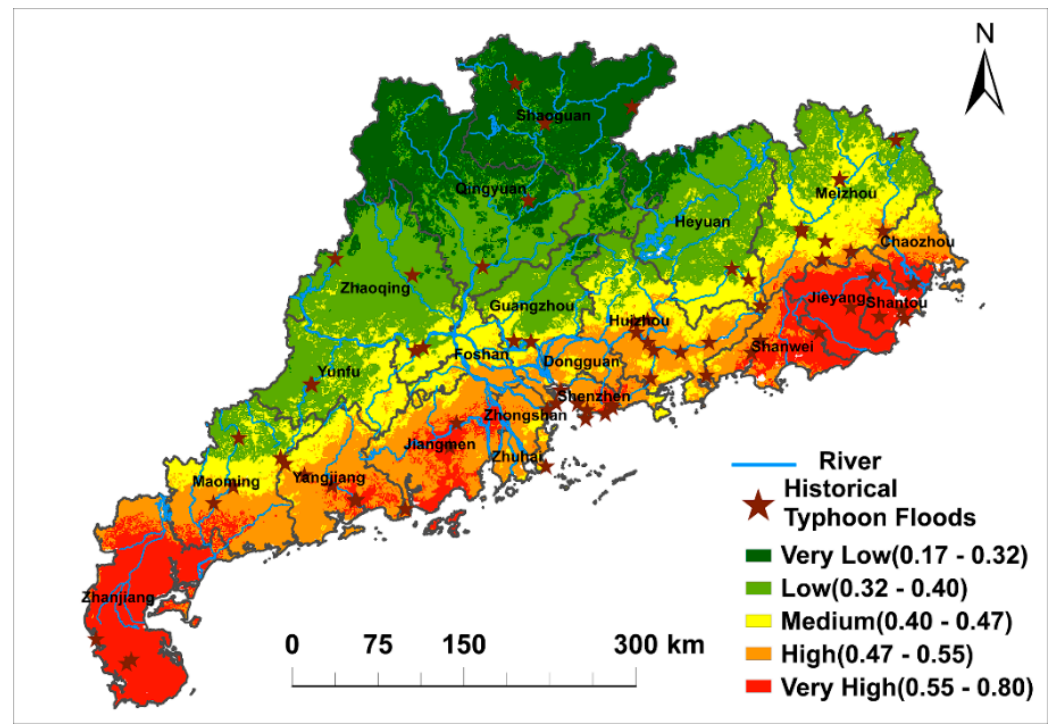

Figure 9. Historical floods induced by typhoons overlayed with a typhoon flood risk index map.

According to the results, a total of 20 floods occurred in very high risk areas, 26 occurred in higher risk areas, 16 occurred in medium risk areas, 13 occurred in low risk areas, and two occurred in very low risk areas. This means that the four-fifths of typhoon disasters occurred in areas with medium level risk or greater, and three-fifths of typhoon disasters occurred in areas with higher risk or greater. According to historical records, the typhoon flood disasters usually happened in the areas near the coastline or alongside the rivers. The results show that the risk assessed map is in good agreement with the historical records, as most of the floods caused by typhoons occurred in high and above risk areas. However, there are still some historical typhoon floods which occurred in the very low risk areas of the assessed map, and these floods mainly happened alongside the rivers in the very low risk areas. The reason why some places near the rivers have been defined as low risk areas could be explained as follows: The weight of drainage density is lower than the weight of heavy rainfall's 
frequencies, and frequencies of heavy rainfall near the coastline are much higher than that inland, so the risk of inland cities is lower than that of coastal cities, but typhoon floods would still happen in low risk areas. Due to limited data, the flood disaster records caused by typhoon rainstorms are not covered all, but the above results are also of certain reference significance. In conclusion, the typhoon flood risk area was calculated by selecting factors from four evaluation aspects and their weights. This method was able to produce accurate results in Guangdong province. It can be seen that the typhoon flood risk area assessment method can be used to accurately predict the possibility of typhoon flood disaster in an area when a typhoon comes.

\subsection{Remaining Deficiencies and Future Research Direction}

However, there are still some deficiencies in this study that we should be aware of and continue to explore in future studies. Firstly, we chose the AHP to determine the weights of 17 evaluation factors, mainly because the AHP is considered to be suitable for producing a layered staggered evaluation index system of the target, but the subjectivity of AHP could not be overlooked. For example, some historical typhoon floods occurred in the very low risk areas because the calculation of weight considered much about the typhoon and its factors and neglected the amount of information and indicator outputting. Future research should combine AHP with other methods, for example, random forests or the entropy weight methods, to reduce the subjectivity. Secondly, the selected indicators were regarded as unrelated to each other, but we did not carry out any calculations to exclude the existence of correlations. In future studies, we will calculate these correlations to make sure that only unrelated indicators were selected for the experiment. Thirdly, we could make use of historical typhoon flood records as a variable or indicator to modify this model and make it more consistent with the actual situation. Besides, the distinction of flood-prone areas could also be carried out based on flood depth, and some researchers have done this before. De Risi (2015) used the topographic wetness index (TWI) threshold to detect the region which was potentially exposed to flood inundation and applied it to a hydraulic inundation model to demonstrate that it was useful for the potentially flood-prone areas zoning in micro and meso-scale [65]. Based on these researches, we could combine the hydraulic inundation model and calculate the flood depth so as to define flood risk during typhoon process.

\section{Conclusions}

This study mapped the spatial distribution of typhoon flood risk in Guangdong province in South China. According to our findings, areas with a very high risk of typhoon floods are mainly located in the coastal areas, including the Pearl River Delta and the Northeast (Chaoshan plains) and West (Zhanjiang, Maoming) of Guangdong province. According to the historical records of typhoon flood disasters, these areas have experienced greater numbers of typhoon flood disasters in the last 15 years. In these areas, the typhoon frequency is high, the elevation and slope are smaller, the distribution of the river network is dense, and the mean typhoon rainfall and heavy rainfall frequencies are high. These factors lead to the higher typhoon flood risk. In contrast, mountainous areas in the Northwest of Guangdong province are classified as areas with a very low to low risk of typhoon flooding, because typhoons dissipate before affecting these areas. The results indicate that the typhoon frequency, typhoon rainstorm frequency, drainage density, elevation, slope, land use type, population density, and urbanization density are the key factors that affect the typhoon flood risk of a particular area. Among them, the factors with large weights based on AHP are usually those related to precipitation, such as the frequency of heavy rainfall and the mean daily rainfall, followed by those related to the terrain and river network. The number of indicators in the model determines the weight of each evaluation factor. Generally speaking, if the number of evaluation factors is less than ten, it will generate an unrepresentative weight dominated by a single weight, thus increasing the possibility of overestimating some factors [60]. It is usually recommended to select more than ten indicators that are representative of each other but not related to each other. In this study, the disaster risk of flood-prone areas was calculated through a combination of qualitative and quantitative methods, so the results 
visually show the risk level of the study areas. Considering fully quantitative methods, Life Cycle Cost (LCC) and Return on Investment (ROI) were used as decision variables to calculate the potential loss and impact [20]. So we could consider an indicator to quantify the typhoon flood disaster loss and make it useful for mitigation strategies.

The typhoon flood risk map has good coherence to historical typhoon flood records, so the adopted method could be applied to help with the early warning and prediction of typhoon flood disasters, so as to reduce personnel injuries and property losses as well as to aid in long-term land planning. However, more extensive tests should be carried out in other areas with different climatic conditions and topographic characteristics to identify typhoon flood risk areas. In addition, the importance of each assessment indicator and the number of representative assessment indicators to be included in the assessment model should be further identified based on the historical typhoon flood records of the area.

Author Contributions: Data curation, J.Z.; Formal analysis, J.Z.; Funding acquisition, Y.C.; Investigation, J.Z.; Project administration, Y.C.; Supervision, Y.C.; Validation, J.Z.; Writing—original draft, J.Z.; Writing-review \& editing, Y.C.

Acknowledgments: This study was supported by the National Key Research and Development Program of China (funding no. 2017YFC1502702).

Conflicts of Interest: The authors declare no conflict of interest.

\section{Appendix A}

The judgment matrix and consistency ratio (CR) of different aspect layers using AHP method are shown in Tables A1-A5.

Table A1. The judgment matrix and consistency ratios of typhoon flood risk.

\begin{tabular}{ccccc}
\hline Typhoon Flood Risk & Hazard & Sensitivity & Vulnerability & Restorability \\
\hline Hazard & 1 & 3 & 3 & 4 \\
Sensitivity & $1 / 3$ & 1 & 1 & 3 \\
Vulnerability & $1 / 3$ & 1 & 1 & 2 \\
Restorability & $1 / 4$ & $1 / 3$ & $1 / 2$ & 1 \\
\hline
\end{tabular}

$\mathrm{CR}=0.0235<0.1$.

Table A2. The judgment matrix and consistency ratios of the severity of typhoon flood hazard causing factors.

\begin{tabular}{ccccc}
\hline Hazard & $\begin{array}{c}\text { Mean Maximum } \\
\text { Wind }\end{array}$ & $\begin{array}{c}\text { Mean Daily } \\
\text { Rainfall }\end{array}$ & $\begin{array}{c}\text { Frequencies of } \\
\text { Heavy Rainfall }\end{array}$ & $\begin{array}{c}\text { Typhoon } \\
\text { Frequencies }\end{array}$ \\
\hline Mean maximum wind & 1 & $1 / 5$ & $1 / 8$ & $1 / 2$ \\
Mean daily rainfall & 5 & 1 & $1 / 3$ & 3 \\
Frequency of heavy rainfall & 8 & 3 & 1 & 6 \\
Typhoon frequency & 2 & $1 / 3$ & $1 / 6$ & 1 \\
\hline & $\mathrm{CR}=0.0179<0.1$.
\end{tabular}


Table A3. The judgment matrix and consistency ratios of the sensitivity of hazard breeding environments.

\begin{tabular}{ccccc}
\hline Sensitivity & Elevation & Slope & Drainage Density & $\begin{array}{c}\text { Vegetation } \\
\text { Coverage }\end{array}$ \\
\hline Elevation & 1 & $1 / 3$ & $1 / 7$ & $1 / 2$ \\
Slope & 3 & 1 & $1 / 2$ & 2 \\
Drainage density & 7 & 2 & 1 & 4 \\
Vegetation coverage & 2 & $1 / 2$ & $1 / 4$ & 1 \\
\hline
\end{tabular}

$\mathrm{CR}=0.0029<0.1$.

Table A4. The judgment matrix and consistency ratios of the vulnerability of hazard bearing objects.

\begin{tabular}{ccccc}
\hline Vulnerability & $\begin{array}{c}\text { Cultivated Land } \\
\text { than }\end{array}$ & $\begin{array}{c}\text { Population } \\
\text { Density }\end{array}$ & $\begin{array}{c}\text { Industrial } \\
\text { Production }\end{array}$ & $\begin{array}{c}\text { Urbanization } \\
\text { Density }\end{array}$ \\
\hline Cultivated land than & 1 & $1 / 3$ & 1 & 1 \\
Population density & 3 & 1 & 4 & 4 \\
Industrial production & 1 & $1 / 4$ & 1 & 2 \\
Urbanization density & 1 & $1 / 4$ & $1 / 2$ & 1 \\
\hline
\end{tabular}

Table A5. The judgment matrix and consistency ratios of the hazard prevention and mitigation capability.

\begin{tabular}{cccccc}
\hline Restorability & $\begin{array}{c}\text { Hospital Bed } \\
\text { Capacity }\end{array}$ & $\begin{array}{c}\text { Medical Staff } \\
\text { Number }\end{array}$ & $\begin{array}{c}\text { Gauging Station } \\
\text { Density }\end{array}$ & $\begin{array}{c}\text { GDP Per } \\
\text { Capita }\end{array}$ & $\begin{array}{c}\text { Road } \\
\text { Density }\end{array}$ \\
\hline Hospital bed capacity & 1 & 1 & $1 / 2$ & 3 & 3 \\
Medical staff number & 1 & 1 & $1 / 3$ & 2 & 2 \\
Gauging station density & 2 & 3 & 1 & 4 & 3 \\
GDP per capita & $1 / 3$ & $1 / 2$ & $1 / 4$ & 3 & $1 / 3$ \\
Road density & $1 / 3$ & $1 / 2$ & $1 / 3$ & 1 \\
\hline
\end{tabular}

\section{References}

1. Hoque, M.A.-A.; Phinn, S.; Roelfsema, C.; Childs, I. Assessing tropical cyclone risks using geospatial techniques. Appl. Geogr. 2018, 98, 22-33. [CrossRef]

2. Nott, J. Palaeotempestology: The study of and implications Review article prehistoric tropical cyclones-A review for hazard assessment. Environ. Int. 2004, 30, 433-447. [CrossRef] [PubMed]

3. Rumpf, J.; Weindl, H.; Hoppe, P.; Rauch, E.; Schmidt, V. Tropical cyclone hazard assessment using model-based track simulation. Nat. Hazards 2009, 48, 383-398. [CrossRef]

4. $\quad$ Ren, R.; Yu, D.Q.; Wang, L.X.; Wang, K.; Wang, H.; He, S.Y. Typhoon triggered operation tunnel debris flow disaster in coastal areas of SE China. Geomat. Nat. Hazards Risk 2019, 10, 562-575. [CrossRef]

5. Ni, X.; Zhang, Q.H.; Ma, D.; Wu, L.G.; Ren, F.M. Climatology and trends of tropical cyclone high wind in mainland China: 1959-2011. J. Geophys. Res. Atmos. 2015, 120, 12378-12393. [CrossRef]

6. Zhang, X.R.; Li, Y.; Zhang, D.L.; Chen, L.S. A 65-yr Climatology of Unusual Tracks of Tropical Cyclones in the Vicinity of China's Coastal Waters during 1949-2013. J. Appl. Meteorol. Climatol. 2018, 57, 155-170. [CrossRef]

7. Huang, Y.; Cheng, $\mathrm{H}$. The impact of climate change on coastal geological disasters in southeastern China. Nat. Hazards 2012, 65, 377-390. [CrossRef]

8. Yin, J.; Yin, Z.; Xu, S. Composite risk assessment of typhoon-induced disaster for China's coastal area. Nat. Hazards 2013, 69, 1423-1434. [CrossRef]

9. Yu, J.H.; Xue, H.X.; Song, J. Tropical cyclone potential hazard in Southeast China and its linkage with the East Asian westerly jet. Asia Pac. J. Atmos. Sci. 2017, 53, 295-304. [CrossRef] 
10. Zhao, Y.; Gong, Z.W.; Wang, W.H.; Luo, K. The comprehensive risk evaluation on rainstorm and flood disaster losses in China mainland from 2004 to 2009: Based on the triangular gray correlation theory. Nat. Hazards 2014, 71, 1001-1016. [CrossRef]

11. Penades-Pla, V.; Garcia-Segura, T.; Marti, J.V.; Yepes, V. A Review of Multi-Criteria Decision-Making Methods Applied to the Sustainable Bridge Design. Sustainability 2016, 8, 1295. [CrossRef]

12. Chan, J.C.L.; Shi, J.E. Frequency of typhoon landfall over Guangdong Province of China during the period 1470-1931. Int. J. Climatol. 2000, 20, 183-190. [CrossRef]

13. Zhang, Q.; Zhang, W.; Chen, Y.D.; Jiang, T. Flood, drought and typhoon disasters during the last half-century in the Guangdong province, China. Nat. Hazards 2011, 57, 267-278. [CrossRef]

14. Wang, X.N.; Wang, X.W.; Zhai, J.Q.; Li, X.C.; Huang, H.B.; Li, C.M.; Zheng, J.; Sun, H.Y. Improvement to flooding risk assessment of storm surges by residual interpolation in the coastal areas of Guangdong Province, China. Quat. Int. 2017, 453,1-14. [CrossRef]

15. Wang, W.; Xun, H.M.; Zhou, M.G.; Jiang, B.F.; Wang, S.W.; Guo, Q.; Kang, R.H.; Wang, X.; Gifty, M.; Ma, W. Impacts of Typhoon 'Koppu' on Infectious Diarrhea in Guangdong Province, China. Biomed. Environ. Sci. 2015, 28, 920-923.

16. Cornell, C.A. Engineering Seismic Risk Analysis. Bull. Seismol. Soc. Am. 1968, 58 (Suppl. 1), $183-188$.

17. Maskrey, A. Disaster Mitigation: A Community Based Approach; Oxfam International: Oxford, UK, 1989.

18. Blaikie, P.M. Post-modernism and global environmental change. Glob. Environ. Chang. 1996, 6, 81-85. [CrossRef]

19. Crichton, D. UK and global insurance responses to flood hazard. Water Int. 2002, 27, 119-131. [CrossRef]

20. De Risi, R.; De Paola, F.; Turpie, J.; Kroeger, T. Life Cycle Cost and Return on Investment as complementary decision variables for urban flood risk management in developing countries. Int. J. Disaster Risk Reduct. 2018, 28, 88-106. [CrossRef]

21. Williams, A.; Archer, D. The use of historical flood information in the English Midlands to improve risk assessment. Hydrol. Sci. J. 2002, 47, 67-76. [CrossRef]

22. Polomcic, D.; Bajic, D.; Ratkovic, J. Assessment of Historical Flood Risk to the Groundwater Regime: Case Study of the Kolubara Coal Basin, Serbia. Water 2018, 10, 588. [CrossRef]

23. Kazakis, N.; Kougias, I.; Patsialis, T. Assessment of flood hazard areas at a regional scale using an index-based approach and Analytical Hierarchy Process: Application in Rhodope-Evros region, Greece. Sci. Total Environ. 2015, 538, 555-563. [CrossRef] [PubMed]

24. Chen, Y.R.; Yeh, C.H.; Yu, B.F. Integrated application of the analytic hierarchy process and the geographic information system for flood risk assessment and flood plain management in Taiwan. Nat. Hazards 2011, 59, 1261-1276. [CrossRef]

25. Xiao, Y.; Yi, S.; Tang, Z. Integrated flood hazard assessment based on spatial ordered weighted averaging method considering spatial heterogeneity of risk preference. Sci. Total Environ. 2017, 599-600, 1034-1046. [CrossRef]

26. Ouma, Y.; Tateishi, R. Urban Flood Vulnerability and Risk Mapping Using Integrated Multi-Parametric AHP and GIS: Methodological Overview and Case Study Assessment. Water 2014, 6, 1515-1545. [CrossRef]

27. Islam, M.M.; Sado, K. Flood hazard assessment in Bangladesh using NOAA AVHRR data with geographical information system. Hydrol. Process. 2000, 14, 605-620. [CrossRef]

28. Islam, M.D.M.; Sado, K. Development of flood hazard maps of Bangladesh using NOAA-AVHRR images with GIS. Hydrol. Sci. J. 2000, 45, 337-355. [CrossRef]

29. Du, S.Q.; Van Rompaey, A.; Shi, P.J.; Wang, J.A. A dual effect of urban expansion on flood risk in the Pearl River Delta (China) revealed by land-use scenarios and direct runoff simulation. Nat. Hazards 2015, 77, 111-128. [CrossRef]

30. Li, M.Y.; Wu, W.; Wang, J.; Che, Z.M.; Xie, Y.L. Simulating and mapping the risk of surge floods in multiple typhoon scenarios: A case study of Yuhuan County, Zhejiang Province, China. Stoch. Environ. Res. Risk A 2017, 31, 645-659. [CrossRef]

31. Yao, L.; Wei, W.; Yu, Y.; Xiao, J.; Chen, L.D. Rainfall-runoff risk characteristics of urban function zones in Beijing using the SCS-CN model. J. Geogr. Sci. 2018, 28, 656-668. [CrossRef]

32. Yang, X.L.; Ding, J.H.; Hou, H. Application of a triangular fuzzy AHP approach for flood risk evaluation and response measures analysis. Nat. Hazards 2013, 68, 657-674. [CrossRef] 
33. Jiang, W.; Deng, L.; Chen, L.; Wu, J.; Li, J. Risk assessment and validation of flood disaster based on fuzzy mathematics. Prog. Nat. Sci. 2009, 19, 1419-1425. [CrossRef]

34. Wahab, R.; Tiong, R. Multi-variate residential flood loss estimation model for Jakarta: An approach based on a combination of statistical techniques. Nat. Hazards 2017, 86, 779-804. [CrossRef]

35. Hsu, T.-H.; Pan, F.F.C. Application of Monte Carlo AHP in ranking dental quality attributes. Expert Syst. Appl. 2009, 36, 2310-2316. [CrossRef]

36. Dario, A.; Sicim, H.O.; Balikci, E. A new approach for dopant distribution and morphological stability in crystals grown by the axial heat processing (AHP) technique. J. Cryst. Growth 2011, 337, 65-71. [CrossRef]

37. Ba-Shammakh, M.S. A Decision Support Tool for Multi-Pollutants Reduction in Cement Industry Using Analytic Hierarchy Process (Ahp). Can. J. Chem. Eng. 2011, 89, 1508-1515. [CrossRef]

38. De Felice, F. Research and applications of AHP/ANP and MCDA for decision making in manufacturing. Int. J. Prod. Res. 2012, 50, 4735-4737. [CrossRef]

39. Bian, F.L.; Cai, H.Q. Choice of Crack Repairing Material for Asphalt Pavement Based on AHP. J. Test. Eval. 2012, 40, 1144-1147. [CrossRef]

40. Saeed, M.O.; Ahamad, M.S.S.; Aziz, H.A.; Ahmad, S.Z. An integrated AHP-GIS technique for landfill siting: A case study in Malaysia. Kuwait J. Sci. Eng. 2012, 39, 23-46.

41. Stefanidis, S.; Stathis, D. Assessment of flood hazard based on natural and anthropogenic factors using analytic hierarchy process (AHP). Nat. Hazards 2013, 68, 569-585. [CrossRef]

42. Apel, H.; Thieken, A.H.; Merz, B.; Bloschl, G. Flood risk assessment and associated uncertainty. Nat. Hazards Earth Syst. Sci. 2004, 4, 295-308. [CrossRef]

43. Kooistra, L.; Huijbregts, M.A.J.; Ragas, A.M.J.; Wehrens, R.; Leuven, R.S.E.W. Spatial variability and uncertainty in ecological risk assessment: A case study on the potential risk of cadmium for the little owl in a Dutch river flood plain. Environ. Sci. Technol. 2005, 39, 2177-2187. [CrossRef]

44. Cao, C.; Wang, Q.; Chen, J.P.; Ruan, Y.K.; Zheng, L.J.; Song, S.Y.; Niu, C.C. Landslide Susceptibility Mapping in Vertical Distribution Law of Precipitation Area: Case of the Xulong Hydropower Station Reservoir, Southwestern China. Water 2016, 8, 270. [CrossRef]

45. Huang, C.F.; Da, R.A. Fuzzy risks and an updating algorithm with new observations. Risk Anal. 2008, 28, 681-694. [CrossRef]

46. Roder, G.; Sofia, G.; Wu, Z.; Tarolli, P. Assessment of Social Vulnerability to Floods in the Floodplain of Northern Italy. Weather Clim. Soc. 2017, 9, 717-737. [CrossRef]

47. Karagiorgos, K.; Thaler, T.; Heiser, M.; Hubl, J.; Fuchs, S. Integrated flash flood vulnerability assessment: Insights from East Attica, Greece. J. Hydrol. 2016, 541, 553-562. [CrossRef]

48. National Meteorological Information Center. Available online: http://data.cma.cn/ (accessed on 11 December 2018).

49. CMA Tropical Cyclone Data Center. Available online: http://tcdata.typhoon.org.cn/ (accessed on 13 December 2018).

50. Ying, M.; Zhang, W.; Yu, H.; Lu, X.Q.; Feng, J.X.; Fan, Y.X.; Zhu, Y.T.; Chen, D.Q. An Overview of the China Meteorological Administration Tropical Cyclone Database. J. Atmos. Ocean. Technol. 2014, 31, 287-301. [CrossRef]

51. Resource and Environment Data Cloud Platform. Available online: http://www.resdc.cn/Default.aspx (accessed on 10 December 2018).

52. SRTM Data. Available online: http://srtm.csi.cgiar.org/ (accessed on 5 December 2018).

53. Guangdong Bureau of Statistics. Available online: http://www.gdstats.gov.cn/ (accessed on 17 December 2018).

54. Socioeconomic Data and Applications Center (SEDAC). Available online: http://sedac.ciesin.columbia.edu/ data/collection/gpw-v4 (accessed on 15 December 2018).

55. OpenStreetMap. Available online: https://www.openstreetmap.org (accessed on 12 December 2018).

56. Guo, E.; Zhang, J.; Ren, X.; Zhang, Q.; Sun, Z. Integrated risk assessment of flood disaster based on improved set pair analysis and the variable fuzzy set theory in central Liaoning Province, China. Nat. Hazards 2014, 74, 947-965. [CrossRef]

57. Wang, Y.M.; Liu, J.; Elhag, T.M.S. An integrated AHP-DEA methodology for bridge risk assessment. Comput. Ind. Eng. 2008, 54, 513-525. [CrossRef]

58. Tesfamariam, S.; Sadiq, R. Risk-based environmental decision-making using fuzzy analytic hierarchy process (F-AHP). Stoch. Environ. Res. Risk A 2006, 21, 35-50. [CrossRef] 
59. Li, F.W.; Phoon, K.K.; Du, X.L.; Zhang, M.J. Improved AHP Method and Its Application in Risk Identification. J. Constr. Eng. Manag. 2013, 139, 312-320. [CrossRef]

60. Mahmoud, S.H.; Gan, T.Y. Multi-criteria approach to develop flood susceptibility maps in arid regions of Middle East. J. Clean. Prod. 2018, 196, 216-229. [CrossRef]

61. Zuo, R.; Chen, X.J.; Li, X.B.; Shan, D.; Yang, J.; Wang, J.S.; Teng, Y.G. Distribution, genesis, and pollution risk of ammonium nitrogen in groundwater in an arid loess plain, northwestern China. Environ. Earth Sci. 2017, 76, 629. [CrossRef]

62. Wang, Y.; Li, Z.; Tang, Z.; Zeng, G. A GIS-Based Spatial Multi-Criteria Approach for Flood Risk Assessment in the Dongting Lake Region, Hunan, Central China. Water Resour. Manag. 2011, 25, 3465-3484. [CrossRef]

63. Hajkowicz, S.; Collins, K. A review of multiple criteria analysis for water resource planning and management. Water Resour. Manag. 2007, 21, 1553-1566. [CrossRef]

64. Ayalew, L.; Yamagishi, H. The application of GIS-based logistic regression for landslide susceptibility mapping in the Kakuda-Yahiko Mountains, Central Japan. Geomorphology 2005, 65, 15-31. [CrossRef]

65. De Risi, R.; Jalayer, F.; De Paola, F. Meso-scale hazard zoning of potentially flood prone areas. J. Hydrol. 2015, 527, 316-325. [CrossRef]

(C) 2019 by the authors. Licensee MDPI, Basel, Switzerland. This article is an open access article distributed under the terms and conditions of the Creative Commons Attribution (CC BY) license (http://creativecommons.org/licenses/by/4.0/). 